\title{
Clinical work with people affected by public care or adoption
}

\author{
Thomas Hillen \& Hannah Wright
}

\begin{abstract}
SUMMARY
Most individuals who have lived in foster homes, residential care or adoptive families for substantial periods ('people affected by public care or adoption') show normal psychological adjustment as adults, although rates of mental disorders, hospital admission and suicide are increased. Research focusing on the experiences of this group of people can help professionals better understand their behaviour and attitude towards help. Psychiatric symptoms can be multifaceted, including complex trauma presentations. The specific mental health needs of this population are increasingly being recognised in child and adolescent mental health services but less so in adult services. In this article we describe life experiences of people affected by public care or adoption, examine the lifelong impact of these experiences on mental health and functioning, and offer practical suggestions for clinical work with them.
\end{abstract}

\section{LEARNING OBJECTIVES}

- Appreciate the heterogeneity of experiences of people who have been adopted or in public care

- Understand the impact of these experiences on the symptoms, behavioural presentation and attitude to help of young people and adults

- Consider the implications for clinical work and know how to take a personal history from individuals affected by care or adoption

\section{DECLARATION OF INTEREST}

None

Many psychiatrists regularly, but not necessarily knowingly, encounter patients who were separated from their birth families as they grew up. Previous reviews have examined the consequences for children's mental health (Richardson 2003; Rushton 2007), and in this selective review we consider the impact on older adolescents and adults and offer suggestions for clinical work with them.

\section{Proportion of the UK population affected by public care or adoption}

An individual's journey through the care system will be influenced by the political and social landscape into which they were born, and the extent to which securing permanency with alternative carers was preferred to supporting rehabilitation with birth families (Lewis 2004). Changes in government policy have affected the number of children in care and adopted over time. On 31 March 2013, 68110 children were in public care in England. Their number had increased steadily each year and was higher than at any time since 1985. The number of children placed for adoption increased by 25\% between 2009 and 2013, although their overall number remained small, at 3350 (Department for Education 2013a).

In 2013, 10080 children left the care system because they returned home to their parents or relatives. However, reunification did not necessarily lead to stability. Sinclair (2006) found that $40 \%$ of children in public care had entered care on more than one occasion. Maltreated children who returned to their parents were more likely to experience further abuse or neglect (Sinclair 2005) and had poorer psychosocial outcomes (Biehal 2007).

This article concerns individuals who remained separated from their families for substantial periods and lived in foster homes, residential care or adoptive families. For brevity, we refer to such individuals as people affected by public care or adoption.

Although the numbers of children in care or adopted in England are routinely recorded, it is difficult to estimate the population of adult alumni. Studies based on the 1970 British Birth Cohort Study have found that $4-5 \%$ of the population had been placed in public care at some point during their lives, but this included both short- and longterm episodes of care (Viner 2005; Dregan 2011, 2012). No other systematic survey data have been reported in relation to the proportion of individuals in the general population who spent part of their childhood in public care or who were adopted.

\section{Separation from birth families and its impact on mental health}

Why, how and the age at which children and young people are separated from their birth families have major implications for their adult lives. The main reasons for entry into care in high-income countries are child maltreatment
Thomas Hillen has practised as consultant in child and adolescent psychiatry and is currently undergoing further training in medical psychotherapy at the Tavistock Clinic in London. He continues to work in the field of child maltreatment within and outside the National Health Service and offers specialist assessments and interventions to individuals and organisations Hannah Wright is an assistant psychologist at the Tavistock Clinic. She works with families involved with child protection services and her research interests include outcomes for maltreated children. Correspondence Dr Thomas Hillen, Tavistock Clinic, 120 Belsize Park, London NW3 5AB, UK. Email thillen2@tavi-port.nhs.uk. 
and family dysfunction, often in the context of parental mental illness, substance misuse, domestic violence, poverty and low educational achievement (Gilbert 2009). Consequently, genetic and perinatal risk factors for mental illness are increased among these individuals. The effects of maternal stress and substance misuse during pregnancy, and their interaction with parenting and environmental factors, are increasingly better understood (Bergman 2007; Minnes 2011). Early childhood adversity such as exposure to trauma and family dysfunction have been linked to enduring neurobiological changes and the pathogenesis of mental disorders (Rosenberg 2007; Lu 2008; McCrory 2010).

A systematic review examining the relationship between maltreatment and outcome concluded that neglect was at least as harmful as physical or sexual abuse (Gilbert 2009). The specific nature of subsequent difficulties did not appear to be determined by the type of abuse suffered. A strong association was found between maltreatment and behavioural problems/criminality, posttraumatic stress disorder (PTSD) and obesity; and a moderate association with low educational/ vocational achievement, depression, attempted suicide, alcohol problems and prostitution/sex trading. Exposure to multiple types and instances of maltreatment had a cumulative impact on risk of negative outcomes. However, no individual should be viewed as a 'lost cause' on the basis of their history of maltreatment: the risk is linear, not threshold (Appleyard 2005; Gilbert 2009).

Removing a child from a maltreating family is not without cost. The separation from the family

\section{BOX 1 Trauma, loss and shame caused by the separation from the birth family}

Traumatic removal from the birth family

Several children expressed embarrassment and anger at being taken from school. One child said, 'The police should have waited until I got out of school ... They shouldn't have told us [only] ten days. Or [they should] let us go home and get our stuff. Or at least not take us away without our parents knowing. It seemed like we were going to jail' (Johnson 1995).

Stigma and devaluation

One former foster child said: 'There's a perception that ... foster kids ... if they're not with their mother or father, that means no one wants them, and no one wants them for a reason, so I think they're almost seen as a lost cause' (Hochman 2004).

Sense of loss, shame and rejection One young person told researchers: 'I felt unwanted, I felt useless ... And that ... obviously makes you feel like crap, she's supposed to be your mam and supposed to love you ... for a few years I thought it was all my fault and it was all what l'd done, so I felt useless' (Luke 2008).

One young person missed family and friends: 'I'm 120 miles away from ma m8s and ma mum'. Another said: 'Any child would prefer to live with their natural parents'; and another simply said: 'I get homesick and just wanna be home' (Morgan 2009). is often traumatic and represents a significant childhood disruption (Eagle 1994; Toth 1997; Wegar 2000) (Box 1). However, the quality of the care that children receive after long-term separation from their birth families has also been recognised as an important determinant of their adult mental health, as will be discussed below (Kessler 2008; Wicks 2010).

It is important to note that, although children are removed from their birth families with the aim of ending abuse and neglect, this is unfortunately not always achieved. A regrettable repetition of abuse and neglect can occur in their new homes (Gallagher 1999; Skuse 2003). Contributing factors are thought to include the high level of behavioural difficulties in these children, limited training and support for adoptive parents, foster carers and residential workers, and an insufficient acknowledgement of how difficult it can be to care for these children (HM Government 2006).

\section{Experience of public care and adoption, and mental health outcomes}

Epidemiological studies have rarely focused on individuals affected by public care or adoption as one group, and the majority have examined the two groups separately. Different types of placement vary in terms of how much they offer an experience of family membership and opportunities to form selective attachments. Early adoptive placements usually offer the greatest normality, followed by late adoptions and foster placements (Howe 2001).

Residential care has the disadvantage of multiple caregivers, shifts, handovers and few chances for selective attachments (Yang 2007). However, it is important to avoid overgeneralisations concerning the experiences of particular individuals who were affected by these systems.

\section{The experience of public care}

Although psychiatrists are more likely to encounter individuals who faced adversity while going through the care system, they should bear in mind that the majority of individuals in care give a positive account of their experiences. For instance, one study found that $90 \%$ of foster children liked their foster carers (Chapman 2004) and another reported that $81.5 \%$ of children in out-of-home care felt 'happy' or 'very happy' with their current living arrangements (Wilson 1999). Children appreciated the safety and better conditions in their foster homes (Box 2). Over half of the children participating in one survey agreed with the statement that their present foster placement was 'definitely the right one for them' (Johnson 1995). Another study concluded that children in care felt 
as close to their main caregiver as children living with their birth family (Morgan 2006).

Nevertheless, there are important disadvantages to the care system. One of its most negative characteristics is the high level of instability, transience and unpredictability. Multiple breakdowns of placements, high turnover of social workers and last-minute changes to care plans have been criticised and, as a result, placement stability is now a performance indicator for local authorities in England (HM Government 2006). During 2013, $44 \%$ of foster children experienced a change in placement (Department for Education 2013a).

A comprehensive literature review summarised qualitative research into the experiences of individuals affected by public care (Dickson 2009) (Box 2). It demonstrated how some children find it difficult to feel loved and at home in a foster placement. England's highly regulated and bureaucratic Social Services apparatus cannot respond to the needs and wishes of children in the flexible, pragmatic and collaborative way of ordinary families. Despite their best efforts, social workers may struggle to give children the sense that their feelings matter and are fully considered when making important decisions (Box 2). Many children see multiple professionals stepping in and out of their lives without effecting change for the better. Clinicians should bear this in mind when individuals affected by public care are sceptical about how helpful formal services will be to them.

\section{The mental health of young people and adults affected by public care}

The literature regarding mental disorders among children and young people in public care is extensive. A comprehensive survey in England found that $45 \%$ of school-aged children in public care had a mental disorder, which represented a fivefold increase compared with children living in private households even after adjusting for deprivation (Meltzer 2003; Ford 2007). For children in residential care, the figure was even higher, at $71 \%$ (Ford 2007). Other reviews have reported similarly high levels of mental disorders in children in public care (Tarren-Sweeney 2008; Pecora 2009; Oswald 2010).

Less is known about the mental health of public care alumni in adulthood, although large cohort studies have recently yielded some data. Prospective studies based on the 1970 British Birth Cohort Study showed prevalence rates for psychological malaise/depression, criminality and life dissatisfaction among care alumni that were approximately twice those among the general population (Viner 2005; Dregan 2011).
B0X 2 The experience of foster care
Increased safety and comfort in the foster home

'There is no abuse or hitting in the foster home' (Johnson 1995).

'Foster parents are home and provide food

'The foster home is in a nicer neighbourhood, with a better school' (Johnson 1995).

\section{Instability of placements}

A young person who spent 9 years in foster come home from school, I would just see if my stuff was packed or what - that was the 2004).

\section{Love, support and someone to talk to}

'Sometimes, as a child, you just want to sit and have a hug ... and it was impossible ... there was no emotional support there, there was no one to sit and listen' (Luke 2008).

Feeling at home in a foster placement 'They didn't tend to make you feel as if you fitted in because they had two daughters of their own and you got treated differently and care' (Johnson 1995). care reported: 'I remember every day I would first thing I would go check for' (Hochman
So when they went to family parties and things like that I wasn't invited, so you felt a bit left out and hurt really' (Ward 2005).

'Some of them don't make it like it's your home ... so you've got to ask to get a drink or ask to have a shower ... when everyone else just does what they want. And if they've got their own children there, you feel really different to them' (Luke 2008).

Unresponsive Social Services

'You get asked when you move in to another home, but it doesn't really make a difference' (Morgan 2006)

'You can request things that you want, like more contacts, but that doesn't change (Morgan 2006).

'They don't listen to children' (Leeson 2007). '[l]f I was ever asked "how's it going?" I'd be like "Fine, it's fine". I had a place to sleep, I had food, it's fine. But it was sort of the answers that I'd give were really empty. I've got what I need, when you come from somewhere really bad and you go into [a welfare agency], you're lucky to be where you are ... you don't go and complain' (Tregeagle 2008).
These studies supported earlier findings based on the 1958 National Child Development Study of a link between childhood experience of public care and depressive symptoms in adulthood (Cheung 1997; Buchanan 2000; Power 2002). Adult life trajectories were associated with childhood placement patterns; those with more severe emotional and behavioural difficulties were more likely to have been exposed to longer periods of care and multiple placements in both foster and residential care (Dregan 2012). Overall, however, the UK data suggested that the adverse effects of public care on mental health attenuated somewhat in adult life (Viner 2005).

In contrast, data from US studies suggested that the adverse effects of public care on mental health became more pronounced once alumni exited care (Pecora 2009). For instance, the Casey National Study of more than 1000 foster care alumni found that the 12-month prevalence of PTSD was 21\%, exceeding that of US war veterans. The prevalence of drug dependence and bulimia nervosa among care alumni was seven times higher than in the general population. Rates of depression, panic disorder and social phobia were also increased. The Northwest Alumni Study found that lifetime 
prevalence of mental disorders for adults who had spent 1 year or more in foster care exceeded that in the general population on all nine mental disorders assessed. These findings have prompted calls for dedicated mental healthcare provision for young people and adults who have experienced foster care (Pecora 2010).

Systematic UK mapping data show that 9\% of individuals accessing child and adolescent mental health services (CAMHS) have been accommodated in public care (Barnes 2010). Comparable data for adult care alumni in UK adult mental health services are not available. Researchers in the USA examined adults receiving treatment for schizophrenia and severe mood disorders within public mental health systems. They found that about $40 \%$ of patients had been in public care (Rosenberg 2007; Lu 2008). Services working with vulnerable groups such as substance misusers, homeless people and offenders were the most likely to encounter individuals affected by public care (Pecora 2010). Homeless adults with a history of public care were $70 \%$ more likely than those without such histories to report any psychiatric disorder (Thompson 2012). Although these data come from the USA, they suggest that screening for public care history among clinical populations in the UK could aid the planning and provision of mental health services for these vulnerable groups.

\section{BOX 3}

The experience of adoption

Development of a feeling of belonging to the adoptive family

One young person adopted in middle childhood reported: 'I thought, "Yes, I'm never going to leave here now, I'm going to have a proper family". It gives you a chance to make a new life for yourself, new family and new friends' (Dance 2005).

Another said: 'I could get out of my childhood, the bad parts of my childhood and start again... But it took quite a long time getting my head round it [having a new family]. It took a long time for me to say "mum" and "dad" to them because it didn't feel natural. It just felt weird saying mum and dad to another person but after a while

. a couple of months, I started calling them mum and dad but it still took a long time to get my head round that they were actually my mum and dad' (Dance 2005).

\section{Being different}

Maintaining the difference between an adoptive and conventional family: 'I'Il never accept her as my mum because she isn't to me. I mean I don't really love my real mum either but I don't accept her as my mum' (Dance 2005).

A Korean girl adopted by White American parents said: 'The older I get, the more I realize I can't avoid being Korean. Every time I look into the mirror, I am Korean. When I look at family pictures, I feel that I stand out. I guess it shouldn't bother me, but sometimes it does. Even though I may seem very American ... I want to be distinctly Korean. I know I'm not in terms of having all the Korean traditions, but I don't want people to see me and say, "Because she grew up in a Caucasian family, and because she is very Americanized, she's white". That's not what I want anymore' (Lee 2003).

\section{The experience of adoption}

Adoption services in England and Wales have undergone even more radical changes than the care system over recent decades and the experiences of an individual who was adopted will depend on the era during which they were placed with their new family (Thomas 2013). The Children Act 1975 helped to transform adoption by strangers from a service providing 'the perfect baby' to infertile couples to a service designed to find homes for vulnerable children (Quinton 2012); however, it was not until 2002 that the welfare of the child was made first and paramount in legislation (Lewis 2004). More recently, adoption has been viewed as a way of helping children overcome the negative effects of early deprivation and maltreatment within a reparative family environment (Quinton 2012).

This section focuses mainly on domestic adoptees, since the number of international adoptions is still relatively low in England.

Most adult adoptees report positive experiences of adoption (Box 3). A study of self-reported outcomes and experiences of adults who experienced domestic adoption by strangers indicated that around $70 \%$ did well or very well, while 15-20\% expressed dissatisfaction, with the rest falling somewhere in between (Triseliotis 2005). The majority reported feeling a sense of belonging to their adoptive family and of being loved by their adoptive parents, and these feelings have been linked to emotional health. Adoptees who reported emotional difficulties as a result of adoption attributed their problems to the upbringing in an adoptive home, including emotional distancing from adoptive parents, being treated differently from birth children and being from a different ethnic background than their adoptive parents (Triseliotis 2005). A poorer quality of experience within the adoptive family and a negative view of the adoption were also associated with mid-life mental health problems among international adoptees (Rushton 2013).

Although adoptive placements tend to be more stable than foster placements, one should not assume that all adopted individuals experienced permanence whereas those who were fostered did not. Delays in placing children for adoption have been highlighted regularly over the past 40 years, and many adopted children will have had multiple carers prior to placement (Rowe 1973; Monck 2004). For example, in 1998-1999, 38\% of children had one placement prior to adoption, but $29 \%$ had four or more (Ivaldi 2000).

The first comprehensive study of adoption breakdown in England found lower than expected 
rates and indicated that only about 3 in 100 legalised adoptions broke down over a 12-year period (Selwyn 2014). Breakdown rates were higher once adoptees had reached their teenage years. Other risk factors for disruption included older age at placement, longer waiting period between placement and granting of an adoption order, and poor mental health. Thus, $97 \%$ of young people whose adoptions had broken down showed significant social, emotional or behavioural difficulties compared with $22 \%$ of adoptees whose parents reported that the adoption went well.

Over the past three decades, there has been a move towards greater openness in adoption, and young people today are more likely to have more information about their birth parents. These young people's experiences of adoption are therefore different from those of the adult adoptees that dominate adoption research. However, there is also considerable heterogeneity of experience and adjustment in the open adoption group. Selwyn (2006) found that, although some adoptive parents rated contact with birth parents as beneficial, a significant proportion (45\%) were concerned about its negative emotional and behavioural effects on children. Two-thirds of children had indirect ('letterbox') contact with their birth parents, but very few adoptive parents spoke positively about this.

\section{The mental health of young people and adults affected by adoption}

Research comparing adjustment in fostered and adopted children has tended to favour adoption, although these differences are diminishing because fewer infants and greater numbers of older children with prolonged exposure to maltreatment are being adopted (Triseliotis 2002). A metaanalysis of 35 case-control studies found that rates of externalising and internalising difficulties were mildly elevated among adoptees aged 4-18 years compared with the general population (Juffer 2005). Prevalence rates were higher in domestic adoptees than in international adoptees. The meta-analysis did not consider late adoptions, i.e. school-aged children who were adopted from public care. A study focusing on late adoptions found a high prevalence of behavioural problems, with about one-third of adoptees showing considerable disturbance after a substantial amount of time in their placements (Rushton 2006). Pre-adoption experiences, such as maltreatment or highly depriving institutional care, were also associated with outcome, with the latter particularly affecting physical growth and attachment (Juffer 2005; van Ijzendoorn 2006).
Increased rates of suicidal behaviour, completed suicide, psychiatric admissions, schizophrenia, depression and substance misuse have been described for adults who had been part of national and international adoptions (Hjern 2002; Tieman 2005; von Borczyskowski 2006; Cantor-Graae 2007; Laubjerg 2009; van der Vegt 2009; Yoon 2012), but a meta-analysis of these data is not yet available. Recent data on mental health service usage by adopted individuals are not available. A study conducted over 20 years ago in the USA showed that between 10 and $17 \%$ of psychiatric inpatients, and $5 \%$ of psychotherapy patients, were adopted by non-relatives (Brodzinsky 1992).

\section{Adult vulnerabilities}

\section{Relational functioning and intergenerational patterns}

The impact of separation from birth parents on children's ability to form attachments with alternative caregivers is not yet fully understood. Studies of young infants in foster care (Dozier 2001) and after adoption (Singer 1985) found that levels of secure attachment towards alternative caregivers did not differ from those in biologically intact dyads. Similar results have recently been found in a study of adolescents in foster care (Joseph 2014). However, other studies indicated that negative attachment experiences prior to removal may be carried over into subsequent placements. A metaanalysis found that children adopted after their first birthday showed significantly less attachment security and more attachment disorganisation than their peers (van den Dries 2009).

Relational difficulties may persist into adulthood. For example, care alumni in the USA reported higher levels of psychological aggression, physical assault and sexual coercion in their intimate relationships than the general population (Courtney 2009). Higher divorce rates have been observed in adults in England who had been placed in foster care because of the Second World War, and this was mediated by attachment style (Rusby 2010).

The vast majority of individuals who experience maltreatment do not mistreat their own children (Kaufman 1987; Widom 1989; Dixon 2005). The intergenerational transmission of maltreatment has been widely explored in the literature, but many studies supporting this hypothesis have suffered from weak study designs (Thornberry 2012). A prospective study of 4351 newborns in England found that in the first 13 months 6.7\% of parents with a history of physical and/or sexual abuse were referred to Social Services for 
maltreating their own children, compared with $0.4 \%$ of non-maltreated parents (Dixon 2005). Poor parenting styles, young parenthood, mental illness and domestic violence were associated with the intergenerational transmission of abuse.

Effective interventions to improve parenting skills have been developed and they can help break unhelpful intergenerational cycles (Dretzke 2005). Adult mental health services play a role in supporting parents who have a mental illness and struggle with their parenting even though models of practice are not yet well established (Craig 2003). Protective factors should be considered in assessments, alongside risk factors and parenting styles (Dixon 2009).

\section{Stigma, devaluation and bullying}

The media and general public often see individuals affected by public care or adoption in a negative light (Kline 2006). As children, they often faced a devalued status in a society that defined kinship in genetic terms and viewed alternative family constitutions as second best (Wegar 2000; Fisher 2003). Many had to endure bullying before and after they were removed from their birth families. Bullies may have targeted them because they were 'different', found it hard to stand up for themselves and had fewer people to speak out on their behalf (Dickson 2009). The additional stigma attached to mental health services may lead to denial and non-engagement (Callaghan 2003). Being mindful of these factors might help clinicians when dealing with individuals affected by public care or adoption who are reluctant to accept another role that may

BOX 4 Social disadvantages among young people leaving the care system

- Poverty: the majority of care leavers are benefit recipients and live on or below the poverty line (Vernon 2000)

- Unsuitable housing: although care leavers are entitled to housing, they often live in unsuitable or temporary accommodation (Wade 2006)

- Homelessness: 18-32\% of rough sleepers have been in care (Randall 2002)

- Lack of qualifications: the number of children in public care achieving at least five GCSEs (including English and maths) at grade $A^{*}-C$ rose from $11 \%$ in 2009 to $15.3 \%$ in 2013 , but is still low compared with $58 \%$ of children in the general population (Department for Education 2013b) be associated with a devalued status, such as that of the mental health patient.

\section{Social disadvantage into adulthood}

During the critical stage of transition from adolescence into adulthood, young people affected by public care or adoption may have less support at their disposal than the general population. This applies particularly to those who have come through the public care system, as many adopted young people can draw on the ongoing support of their adoptive families (Wade 2008). In England, care alumni must become independent at the age of 18 years, while most of their peers in the general and adopted population remain living at home into their twenties (Stein 2006).

Young people exiting the English care system are referred to as care leavers and are entitled to extra support until the age of 25 years. However, this support can rarely match that of a caring family. As a consequence, care leavers are at risk of social exclusion and they are overrepresented in the most disadvantaged groups (Wade 2006) (Box 4). It has been suggested that the comparative disadvantages faced by care leavers become less pronounced by middle adulthood (Viner 2005).

\section{Importance of resilience}

Levels of psychological adjustment, self-esteem and educational success in non-clinical samples affected by public care or adoption are similar to those in the general population (Haugaard 1998; Fisher 2003; Merdinger 2005; Juffer 2007). The concept of resilience is used to explain why individuals manage to function competently despite living or having lived in adversity. Research into resilience has demonstrated that the ability to overcome adversity is not something extraordinary found in a few people, but is a common consequence of basic human adaptive systems, the functioning of which can be jeopardised by multiple stressors (Masten 2001).

A study of Romanian orphans has provided evidence for a catch-up in the cognitive and social development of children who move from an extremely neglectful to a supportive environment (Rutter 1998). A review of UK outcome studies concluded that children who were adopted from or looked after by the English care system generally demonstrated improvements in their emotional and behavioural presentation over time, despite entering their placements with significant difficulties (Forrester 2009).

Stein (2005) reviewed studies of care leavers and suggested that they fall into three groups: those who were 'moving on' successfully, who had gained 
resilience through their experiences in and after care; those who had experienced more disruption and instability in the care system, but nevertheless viewed themselves as survivors and were able to make use of support networks on leaving care; and those whose damaging pre-care experiences and associated behavioural difficulties had led to and were compounded by disrupted placements in care and education, whose life chances appeared bleak. Quality of care experience, positive (gradual) transition and after-care support were key factors in resilient outcomes. In line with the 'recovery approach', clinicians can promote the resilience of individuals affected by public care or adoption through therapeutic interventions aimed at enhancing their self-efficacy, improving their problem-solving skills and helping them to find a niche where they can develop their potential (Masten 2001; HM Government 2011).

\section{Implications for clinical work}

\section{Difficulties in diagnosis}

Questions have been raised as to whether conventional diagnostic systems can adequately capture the sometimes multifaceted mental health difficulties experienced by maltreated children (Tarren-Sweeney 2008; DeJong 2010). Symptoms in several domains may not meet threshold criteria for a specific diagnosis but they nonetheless affect functioning (Pincus 2003). It was suggested that a separate diagnostic category of developmental trauma disorder or complex post-traumatic stress disorder might be more suitable to capture the symptomatology resulting from childhood maltreatment and disturbed early attachment histories (van der Kolk 2005; Cloitre 2009; Sar 2011). However, the suggested new category was not added to DSM-5 (American Psychiatric Association 2013).

The American Professional Society on the Abuse of Children warns about simplification and blanket attribution of symptoms to past abuse and attachment disruptions (Chaffin 2006). It suggests that established diagnostic categories should be considered first and that the evidence base pertaining to these should be prioritised when drawing up intervention plans. It discourages the use of unproven therapies such as holding therapy.

\section{Clinical work with children and young people}

Differences in the utilisation of mental health services by fostered and by adopted children have been described by researchers in the USA (Miller 2000; Juffer 2005; Stahmer 2005). The former seemed to be underrepresented and the latter overrepresented in mental health services. Adoptive parents in these studies often came from well-educated backgrounds and proactively sought help for their children's mental health difficulties, whereas the foster children were affected by inadequate detection of difficulties and access to help.

Almost 20 years ago, social workers in the UK reported that placement instability, insufficient funding for services and a lack of confidence in services prevented children in care from accessing support for their mental health difficulties (Phillips 1997). A decade later, an independent review of CAMHS highlighted persistent difficulties in providing the full range of appropriate support for children in public care (Davidson 2008). And just a year ago, adoptive parents reported considerable difficulties in accessing CAMHS support for their children, and huge disparities in local services' recognition of and response to attachment difficulties and symptoms of complex trauma (Selwyn 2014).

Guidelines from NICE (Box 5) recommend that local authorities provide dedicated services to support the mental health of children in public care and ensure that children in unstable, shortterm or transitional placements are not prevented from accessing therapeutic services (NICE 2010). Research is needed to establish whether these recommendations are being met in practice.

A recent review identified eight evidence-based interventions for foster families that had delivered positive results in randomised controlled trials, all of which were developed and tested in the
BOX 5 National recommendations for work with individuals affected by the care system

- Multi-agency 'wrap-around' approach

- Service delivery by dedicated multidisciplinary mental health teams

- Outreach approach

- Mental health professionals sensitive to issues of discrimination, bullying, isolation, self-esteem and identity

- Equal access, including for unaccompanied asylum seekers

- Identify individuals who express distress through passive, withdrawn or compliant behaviour

- Specialist practitioners to support young people during the transition to adult services and liaise with 'leaving care' workers and adult mental health practitioners

(NICE 2010) 
USA (Leve 2012). The majority were based on the Multidimensional Treatment Foster Care (MTFC) programme, which targets the individual, family and service system. Studies examining the effectiveness of such programmes in the UK context are starting to emerge (Tighe 2012; Rhoades 2013). An independent evaluation of MTFC for adolescents (MTFC-A) in England found that this programme was preferable to usual care placements only for a subgroup of adolescents with serious antisocial behaviour problems (Biehal 2012).

\section{Clinical work with adults}

The literature regarding clinical work with individuals affected by public care or adoption once they have reached adulthood is limited. NICE (2010) recognised that multi-agency transition planning between child and adult services is often poor and made suggestions about how to overcome this problem. CAMHS treatment of young people in care should continue until a handover, including an assessment and care plan, has been developed with the relevant adult service.

Some studies have investigated adults with a history of childhood maltreatment in relation to their experience of mental healthcare settings, adherence to treatment and recovery style (Havig 2008; Whetten 2008; Picken 2010). While some reported that a history of maltreatment had negligible effects on health behaviour, others suggested that providers should cater for the specific needs of this group. This related to the

BOX 6 Taking a personal history from someone affected by care or adoption

- Can you tell me what things were like when you were living with your birth family before you came into care/were adopted?

- What happened when you came into care/ were adopted? How old were you? How did you feel about it at the time?

- Do you regard yourself as a part of your birth family? Are you still in contact with your birth family? When did you last see them?

- How many foster carers/placements did you have? What made a good placement? Why did some placements not work out?

- How did you get on with your new family/ carer? Looking back, how easy was it to trust other people (foster carers/adoptive parents and friends)? Did this change over time?
- In what way were social workers and other professionals helpful/unhelpful during your adoption/time in care? How have these experiences influenced your thinking about professionals today?

- Did people respond in the way you wanted once they knew you were in care/ adopted? Did this change over time?

- How ready do you think you were when you moved into independent living and were expected to cope on your own? What was most/least helpful in enabling you to live independently?

- How does having been in care/adopted affect your life now?

- Do you have the support and advice of family, friends or other people to call on when you need help? Whose advice and support are you most likely to seek? safety and privacy of the healthcare environment, the need to keep patients informed about what is going to happen to them, helping patients cope with flashbacks triggered by the actions of health professionals, and providing flexible care in line with patients' needs.

The literature examining transference and countertransference in clinical work with individuals affected by public care or adoption is limited. Clinical experience suggests that patients who experienced cruelty and neglect during childhood may evoke in clinicians a social response that may compromise the care they receive (Emanuel 2002). They can be difficult to like, are easily overlooked or forgotten, instil a sense of therapeutic nihilism, or cause disagreements among those looking after them. The opposite response is also possible and clinicians may be drawn into an unrealistic position of wanting to rescue patients.

When interviewing individuals affected by public care or adoption in a clinical setting, it is important to bear in mind that this is a group with very heterogeneous childhood experiences. A sensitive enquiry into their unique experience can reveal information important for the case formulation. Box 6 outlines the case history information that can advise clinicians about the likely impact of the individual's experience of the care system.

When taking a history, clinicians should pay attention to the possibility of cognitive distortion in relation to historical events and current symptoms. Alongside stigma and feelings of shame, patients' attachment styles may be implicated in symptom reporting (Wearden 2005; Browne 2007). For example, memory lapses, minimising negative aspects of past experiences and denial of the personal impact of past relationships are characteristic of attachment difficulties (Bartholomew 1998). At the same time, clinicians need to steer clear of barraging patients with too many questions because this can easily feel intrusive. Individuals affected by public care or adoption may be accustomed to providing a regularly told, carefully packaged childhood story without many questions asked, and may find genuine interest in their current feelings to be anxiety-provoking (Schofield 2003). Slowly obtaining information over several meetings once a degree of trust has been established may be a useful strategy.

\section{Conclusions}

Awareness of the possible difficult life experiences of individuals affected by public care or adoption both before and after separation from their 
birth families can help professionals to a better understanding of some of their attitudes and behaviours. This can improve the therapeutic alliance as long as it does not inadvertently lead to a reliance on stereotypes (Teal 2009). Clinicians should be careful to avoid either overemphasising or minimising experiences of care and adoption in relation to mental health difficulties (Bonovitz 2006), both in childhood and in later life. Clinical work with this group can be complex, but for clinicians who can maintain a reflective, curious and patient-centred approach, it can also be highly rewarding.

\section{References}

American Psychiatric Association (2013) Diagnostic and Statistical Manual of Mental Disorders (5th edn) (DSM-5). APA.

Appleyard K, Egeland B, van Dulman MHM, et al (2005) When more is not better: the role of cumulative risk in child behavior outcomes. Journal of Child Psychology and Psychiatry, 46: 235-45.

Barnes D, Devanney C, Uglebjerg A, et al (2010) A Profile of Children's Health Services, Child and Adolescent Mental Health Services and Maternity Services in England 2008/9. Durham University.

Bartholomew K, Shaver PR (1998) Methods of assessing adult attachment. In Attachment Theory and Close Relationships (eds JA Simpson, WS Rholes): 25-45. Guilford Press.

Bergman K, Sarkar P, O'Connor TG, et al (2007) Maternal stress during pregnancy predicts cognitive ability and fearfulness in infancy. Journal of the American Academy of Child and Adolescent Psychiatry, 46: 1454-63.

Biehal N (2007) Reuniting children with their families: reconsidering the evidence on timing, contact and outcomes. British Journal of Social Work, 37: 807-23.

Biehal N, Dixon J, Parry E, et al (2012) The Care Placements Evaluation (CaPE) Evaluation of Multidimensional Treatment Foster Care for Adolescents (MTFC-A). Department for Education.

Bonovitz C (2006) Unconscious trauma and the transmission of loss. In Understanding Adoption: Clinical Work with Adults, Children and Parents (eds K Hushion, SB Sherman, D Siskind): 11-34. Rowman \& Littlefield.

Brodzinsky DM, Schechter MD, Marantz R (1992) Being Adopted: The Lifelong Search for Self. Doubleday.

Browne C, Winkelman C (2007) The effect of childhood trauma on later psychological adjustment. Journal of Interpersonal Violence, 22: 684-97.

Buchanan A, Brinke T, Flouri E (2000) Parental background, social disadvantage, public 'care', and psychological problems in adolescence and adulthood. Journal of the American Academy of Child and Adolescent Psychiatry, 39: 1415-23.

Callaghan J (2003) Developing new mental health services for looked after children: a focus group study. Adoption \& Fostering, 27: 51-63.

Cantor-Graae E, Pedersen CB (2007) Risk for schizophrenia in intercountry adoptees: a Danish population-based cohort study. Journal of Child Psychology and Psychiatry, 48: 1053-60.

Chaffin M, Hanson R, Saunders BE, et al (2006) Report of the APSAC task force on attachment therapy, reactive attachment disorder, and attachment problems. Child Maltreatment, 11: 76-89.

Chapman MV, Wall A, Barth RP (2004) Children's voices: the perceptions of children in foster care. American Journal of Orthopsychiatry, 74: 293-304.

Cheung SY, Buchanan A (1997) Malaise score in adulthood of children and young people who have been in care. Journal of Child Psychology and Psychiatry, 38: 575-80.

Cloitre M, Stolbach BC, Herman JL, et al (2009) A developmental approach to complex PTSD: childhood and adult cumulative trauma as predictors of symptom complexity. Journal of Traumatic Stress, 22: 399-408.

Courtney ME, Dworsky A, Lee JS, et al (2009) Midwest Evaluation of the Functioning of Former Foster Youth: Outcomes at Ages 23 and 24. Chapin Hall at the University of Chicago.

Craig EA (2003) Parenting programs for women with mental illness who have young children: a review. Australian and New Zealand Journal of Psychiatry, 38: 923-8.

Dance C, Rushton A (2005) Joining a new family: the views and experiences of young people placed with permanent families during middle childhood. Adoption \& Fostering, 11: 18-28.

Davidson J (2008) Children and Young People in Mind: The Final Report from the National CAMHS Review. Department of Health/Department for Children, Schools \& Families.

DeJong M (2010) Some reflections on the use of psychiatric diagnosis in the looked after or 'in care' child population. Clinical Child Psychology and Psychiatry, 15: 589-99.

Department for Education (2013a) Children Looked After in England, Including Adoption. Department for Education.

Department for Education (2013b) Outcomes for Children Looked After by Local Authorities in England, as at 31 March 2013. Department for Education.

Dickson K, Sutcliffe K, Gough D (2009) The Experiences, Views and Preferences of Looked After Children and Young People and their Families and Carers about the Care System. Evidence for Policy \& Practice Information Centre.

Dixon L, Hamilton-Giachritsis C, Browne KD (2005) Attributions and behaviours of parents abused as children: a mediational analysis of the intergenerational continuity of child maltreatment (Part II). Journal of Child Psychology and Psychiatry, 46: 58-68.

Dixon J (2008) Young people leaving care: health, well-being and outcomes. Child and Family Social Work, 13: 207-17.

Dixon L, Browne K, Hamilton-Giachritsis C (2009) Patterns of risk and protective factors in the intergenerational cycle of maltreatment. Journal of Family Violence, 24: 111-22.

Dozier M, Stoval KC, Albus KE, et al (2001) Attachment for infants in foster care: the role of caregiver state of mind. Child Development, 72 : 1467-77.

Dregan A, Brown J, Armstrong D (2011) Do adult emotional and behavioural outcomes vary as a function of diverse childhood experiences of the public health system? Psychological Medicine, 41: 2213-20.

Dregan A, Gulliford MC (2012) Foster care, residential care and public care placement patterns are associated with adult life trajectories: population-based cohort study. Social Psychiatry and Psychiatric Epidemiology, 47: 1517-26

Dretzke J, Frew E, Davenport C, et al (2005) The effectiveness and costeffectiveness of parent training/education programmes for the treatment of conduct disorder, including oppositional defiant disorder, in children. Health Technology Assessment, 9 (50): 1-233.

Eagle RS (1994) The separation experience of children in long-term care: theory, research, and implications for practice. American Journal of Orthopsychiatry, 64: 421-34.

Emanuel $L$ (2002) Deprivation $\times 3$ : the contribution of organisational dynamics to the 'triple deprivation' of looked-after children. Journal of Child Psychotherapy, 28: 163-79.

Fisher AP (2003) Still 'not quite as good as having your own?' Toward a sociology of adoption. Annual Review of Sociology, 29: 335-61.

Ford T, Vostanis P, Meltzer H, et al (2007) Psychiatric disorder among British children looked after by local authorities: comparison with children living in private households. British Journal of Psychiatry, 190: 319-25.

Forrester D, Goodman K, Cocker C, et al (2009) What is the impact of public care on children's welfare? A review of research findings in England and Wales and their policy implications. Journal of Social Policy, 38: 439-56.

Gallagher B (1999) The abuse of children in public care. Child Abuse Review, 8: 357-65. 
Gilbert R, Widom CS, Browne K, et al (2009) Burden and consequences of child maltreatment in high-income countries. Lancet, 373: 68-81.

Haugaard J (1998) Is adoption a risk factor for the development of adjustment problems? Clinical Psychology Review, 18: 47-69.

Havig K (2008) The health care experiences of adult survivors of child sexual abuse: a systematic review of evidence on sensitive practice. Trauma, Violence \& Abuse, 9: 19-33.

Hjern A, Lindblad F, Vinnerljung B (2002) Suicide, psychiatric illness, and social maladjustment in intercountry adoptees in Sweden: a cohort study. Lancet, 360: 443-48.

HM Government (2006) Care Matters: Transforming the Lives of Children and Young People in Care (Green Paper). TSO (The Stationery Office)

HM Government (2011) No Health without Mental Health: A CrossGovernment Mental Health Outcomes Strategy for People of All Ages. TSO (The Stationery Office)

Hochman G, Hochman A, Miller J (2004) Foster Care: Voices from the Inside. Pew Commission on Children in Foster Care.

Howe D, Shemmings D, Feast J (2001) Age at placement and adult adopted people's experience of being adopted. Child and Family Social Work, 6: 337-49

Ivaldi G (2000) Surveying Adoption: A Comprehensive Analysis of Local Authority Adoptions 1998-1999. British Association for Adoption and Fostering.

Johnson PR, Yoken C, Voss R (1995) Family foster care placement: the child's perspective. Child Welfare, 74: 959-74.

Joseph MA, O'Connor TG, Briskman JA, et al (2014) The formation of secure new attachments by children who were maltreated: an observational study of adolescents in foster care. Development and Psychopathology, 26: 67-80.

Juffer $F$, van ljzendoorn MH (2005) Behavior problems and mental health referrals of international adoptees: a meta-analysis. JAMA, 293: 2501-15.

Juffer $F$, van lizendoorn MH (2007) Adoptees do not lack self-esteem: a meta-analysis of studies on self-esteem of transracial, international, and domestic adoptees. Psychological Bulletin, 133: 1067-83.

Kaufman J, Zigler E (1987) Do abused children become abusive parents? American Journal of Orthopsychiatry, 57: 186-92.

Kessler RC, Pecora PJ, Williams J, et al (2008) Effects of enhanced foster care on the long-term physical and mental health of foster care alumni. Archives of General Psychiatry, 65: 625-33.

Kline SL, Karel Al, Chatterjee K (2006) Covering adoption: genera depictions in broadcast news. Family Relations, 55: 487-98.

Laubjerg M, Christensen AM, Petersson B (2009) Psychiatric status among stepchildren and domestic and international adoptees in Denmark: a comparative nationwide register-based study. Scandinavian Journal of Public Health, 37: 604-12.

Lee RM (2003) The transracial adoption paradox: history, research and counselling implications of cultural socialization. Counselling Psychologist, 31: 711-44.

Lee RE, Whiting JB (2007) Foster children's expressions of ambiguous loss. American Journal of Family Therapy, 35: 417-28.

Leeson C (2007) My life in care: experiences of non-participation in decision-making processes. Child and Family Social Work, 12: 268-77.

Leve LD, Harold GT, Chamberlain P, et al (2012) Practitioner review: Children in foster care - vulnerabilities and evidence-based interventions that promote resilience processes. Journal of Child Psychology and Psychiatry, 53: 1197-211.

Lewis $\mathrm{J}$ (2004) Adoption: the nature of policy shifts in England and Wales, 1972-2002. International Journal of Law, Policy and the Family, 18: 235-55.

Lu W, Mueser KT, Rosenberg SD, et al (2008) Correlates of adverse childhood experiences among adults with severe mood disorders. Psychiatric Services, 59: 1018-26.

Luke N, Coyne SM (2008) Fostering self-esteem: exploring adult recollections on the influence of foster parents. Child and Family Social Work, 13: 402-10.
Masten AS (2001) Ordinary magic: resilience processes in development. American Psychologist, 56: 227-38.

McCrory E, De Brito SA, Viding E (2010) Research review: the neurobiology and genetics of maltreatment and adversity. Journal of Child Psychology \& Psychiatry, 51: 1079-95

Meltzer H, Gatward R, Corbin T, et al (2003) The Mental Health of Young People Looked After by Local Authorities in England. Office for National Statistics.

Merdinger JM, Hines AM, Osterling KL, et al (2005) Pathways to college for former foster youth: understanding factors that contribute to educational success. Child Welfare, 84: 867-96.

Miller BC, Fan X, Grotevant HD, et al (2000) Adopted adolescents' overrepresentation in mental health counseling: adoptees' problems or parents' lower threshold? Journal of the American Academy of Child and Adolescent Psychiatry, 39: 1504-15.

Minnes S, Lang A, Singer L (2011) Prenatal tobacco, marijuana, stimulant, and opiate exposure: outcomes and practice implications. Addiction Science and Clinical Practice, 6: 57-70.

Monck E, Reynolds J, Wigfall V (2004) Using concurrent planning to establish permanency for looked after young children. Child \& Family Social Work, 9: 321-31.

Morgan R (2006) Placements, Decisions and Reviews: A Children's Views Report. Office of the Children's Rights Director.

Morgan R (2009) Life in Children's Homes: A Report of Children's Experiences by the Children's Rights Director for England. Office for Standards in Education, Children's Services and Skills.

National Institute for Health and Care Excellence (2010) Looked-After Children and Young People (Public Health Guidance 28). NICE.

Oswald SH, Heil K, Goldbeck L (2010) History of maltreatment and mental health problems in foster children: a review of the literature. Journal of Pediatric Psychology, 35: 462-72.

Pecora PJ, White CR, Jackson LJ, et al (2009) Mental health of current and former recipients of foster care: a review of recent studies in the USA. Child \& Family Social Work, 14: 132-46.

Pecora PJ, Kessler RC, Williams J, et al (2010) What Works in Foster Care? Key Components of Success from the Northwest Foster Care Alumni Study. Oxford University Press.

Phillips J (1997) Meeting the psychiatric needs of children in foster care: social workers' views. Psychiatric Bulletin, 21: 609-11.

Picken AL, Berry K, Tarrier N, et al (2010) Traumatic events, posttraumatic stress disorder, attachment style, and working alliance in a sample of people with psychosis. Journal of Nervous and Mental Disease, 198: 775-8.

Pincus HA, McQueen LE, Elinson L (2003) Subthreshold mental disorders: nosological and research recommendations. In Advancing DSM: Dilemmas in Psychiatric Diagnosis (eds KA Phillips, MB First, HA Pincus): 129-44. American Psychiatric Association.

Power C, Stansfeld SA, Matthews S, et al (2002) Childhood and adulthood risk factors for socio-economic differentials in psychological distress: evidence from the 1958 British birth cohort. Social Science and Medicine, 55: 1989-2004.

Quinton D (2012) Rethinking Matching in Adoptions from Care: A Conceptual and Research Review. British Association for Adoption and Fostering.

Randall G, Brown S (2002) Helping Rough Sleepers off the Streets. Office of the Deputy Prime Minister.

Rhoades KA, Chamberlain P, Roberts R, et al (2013) MTFC for highrisk adolescent girls: a comparison of outcomes in England and the United States. Journal of Child \& Adolescent Substance Abuse, 22: 435-49

Richardson J, Lelliott P (2003) Mental health of looked after children. Advances in Psychiatric Treatment, 9: 249-56.

Rosenberg SD, Lu W, Mueser KT, et al (2007) Correlates of adverse childhood events among adults with schizophrenia spectrum disorders. Psychiatric Services, 58: 245-53. 
Rowe J, Lambert L (1973) Children Who Wait: A Study of Children Needing Substitute Families. Association of British Adoption Agencies.

Rusby JS (2010) Effect of childhood age in foster care on the incidence of divorce in adulthood. Journal of Family Psychology 24: 101-4.

Rushton A, Dance C (2006) The adoption of children from public care: a prospective study of outcome in adolescence. Journal of the American Academy of Child and Adolescent Psychiatry, 45: 877-83.

Rushton A (2007) Outcomes of adoption from public care: research and practice issues. Advances in Psychiatric Treatment, 13: 305-11.

Rushton A, Grant M, Feast J, et al (2013) The British Chinese Adoption Study: orphanage care, adoption and mid-life outcomes. Journal of Child Psychology and Psychiatry, 54: 1215-22.

Rutter M (1998) Developmental catch-up, and deficit, following adoption after severe global early privation: English and Romanian Adoptees (ERA) Study Team. Journal of Child Psychology and Psychiatry, 39: 465-76.

Sar V (2011) Developmental trauma, complex PTSD, and the current proposal of DSM-5. European Journal of Psychotraumatology, doi: 10.3402/ejpt.v2i0.5622 [Epub 7 Mar]

Schofield G (2003) Part of the Family: Pathways through Foster Care. British Association for Adoption and Fostering.

Selwyn J, Sturgess W, Quinton D, et al (2006) Costs and Outcomes of Non-Infant Adoptions. British Association for Adoption and Fostering.

Selwyn J, Wijedasa D, Meakings S (2014) Beyond the Adoption Order: Challenges, Interventions and Adoption Disruption. Research Report. Department for Education.

Sinclair I, Baker C. Wilson K, et al (2005) Foster Children: Where They Go and How They Get On. Jessica Kingsley Publishers.

Sinclair I, Baker C, Lee J (2006) Placement Stability and Change: Report to the DfES. University of York.

Singer LM, Brodzinsky DM, Ramsay D, et al (1985) Mother-infant attachment in adoptive families. Child Development, 56: 1543-51.

Skuse T, Ward H (2003) Outcomes for Looked After Children: Children's Views of Care and Accommodation. Interim Report to the Department of Health. Centre for Child and Family Research.

Social Exclusion Unit (2002) Reducing Offending by Ex-Prisoners. Office of the Deputy Prime Minister.

Stahmer AC, Leslie LK, Hurlburt M, et al (2005) Developmental and behavioral needs and service use for young children in child welfare. Pediatrics, 116: 891-900.

Stein M (2005) Resilience and Young People Leaving Care. Joseph Rowntree Foundation.

Stein M (2006) Research review: young people leaving care. Child \& Family Social Work, 11: 273-79

Tarren-Sweeney M (2008) Retrospective and concurrent predictors of the mental health of children in care. Children and Youth Services Review, 30: 1-25.

Teal CR, Street RL (2009) Critical elements of culturally competent communication in the medical encounter: a review and model. Social Science and Medicine, 68: 533-43.

Thomas C (2013) Adoption for Looked After Children: Messages from Research. An Overview of the Adoption Research Initiative. British Association for Adoption and Fostering.

Thompson RG, Hasin D (2012) Psychiatric disorders and treatment among newly homeless young adults with histories of foster care. Psychiatric Services, 63: 906-12.

Thornberry TP, Knight KE, Lovegrove PJ (2012) Does maltreatment beget maltreatment? A systematic review of the intergenerational literature. Trauma, Violence, \& Abuse, 13: 135-52.

Tieman W, van der Ende J, Verhulst FC (2005) Psychiatric disorders in young adult intercountry adoptees: an epidemiological study. American Journal of Psychiatry, 162: 592-98.

Tighe A, Pistrang N, Casdagli L, et al (2012) Multisystemic therapy for young offenders: families' experiences of therapeutic processes and outcomes. Journal of Family Psychology, 26: 187-97.
Toth SL, Cicchetti D, Macfie J, et al (1997) Representations of self and other in the narratives of neglected, physically abused, and sexually abused preschoolers. Development and Psychopathology, 9: 781-96.

Tregeagle S, Mason J (2008) Service user experience of participation in child welfare case management. Child \& Family Social Work, 13: 391-401.

Triseliotis J (2002) Long-term foster care or adoption? The evidence examined. Child \& Family Social Work, 7: 23-33.

Triseliotis J, Feast J, Kyle F (2005) The Adoption Triangle Revisited: A Study of Adoption, Search and Reunion Experiences. British Association for Adoption and Fostering.

van den Dries L, Juffer F, van IJzendoorn $\mathrm{MH}$, et al (2009) Fostering security? A meta-analysis of attachment in adopted children. Children and Youth Services Review, 31: 410-21.

van ljzendoorn HW, Juffer F (2006) The Emanuel Miller Memorial Lecture 2006: Adoption as intervention. Meta-analytic evidence for massive catch-up and plasticity in physical, socio-emotional, and cognitive development. Journal of Child Psychology and Psychiatry, 27: $1228-45$.

van der Kolk BA (2005) Developmental trauma disorder: a new rational diagnosis for children with complex trauma histories. Psychiatric Annals, 35: $401-8$.

van der Vegt EJ, van der Ende J, Ferdinand RF, et al (2009) Early childhood adversities and trajectories of psychiatric problems in adoptees: evidence for long lasting effects. Journal of Abnormal Child Psychology, 37: $239-49$

Vernon J (2000) Audit and Assessment of Leaving Care Services in London. Department of Health/Rough Sleepers Unit.

Viner RM, Taylor B (2005) Adult health and social outcomes of children who have been in public care: population-based study. Pediatrics, 115: 894-9.

von Borczyskowski A, Hjern A, Lindblad F, et al (2006) Suicidal behaviour in national and international adult adoptees: a Swedish cohort study. Social Psychiatry and Psychiatric Epidemiology, 41: 95-102.

Wade J, Dixon J (2006) Making a home, finding a job: investigating early housing and employment outcomes for young people leaving care. Child \& Family Social Work, 11: 199-208.

Wade $J$ (2008) The ties that bind: support from birth families and substitute families for young people leaving care. British Journal of Social Work, 38: 39-54.

Ward H, Skuse T, Munro ER (2005) The best of times, the worst of times: young people's views of care and accommodation. Adoption \& Fostering, 29: 8-17.

Wearden AJ, Lamberton N, Crook N, et al (2005) Adult attachment, alexithymia, and symptom reporting: an extension to the four category model of attachment. Journal of Psychosomatic Research, 58: 279-88.

Wegar K (2000) Adoption, family ideology, and social stigma: bias in community attitudes, adoption research, and practice. Family Relations, 49: $363-9$.

Whetten K, Reif S, Whetten R, et al (2008) Trauma, mental health, distrust, and stigma among HIV-positive persons: implications for effective care. Psychosomatic Medicine, 70: 531-8.

Wicks S, Hjern A, Dalman C (2010) Social risk or genetic liability for psychosis? A study of children born in Sweden and reared by adoptive parents. American Journal of Psychiatry, 167: 1240-6.

Widom CS (1989) The cycle of violence. Science, 244: 160-66.

Wilson L, Conroy J (1999) Satisfaction of children in out-of-home care. Child Welfare, 78: 53-68.

Yang M, Ullrich S, Roberts A, et al (2007) Childhood institutional care and personality disorder traits in adulthood: findings from the British national surveys of psychiatric morbidity. American Journal of Orthopsychiatry, 77: $67-75$

Yoon G. Westermeyer J, Warwick M, et al (2012) Substance use disorders and adoption: findings from a national sample. PLoS one, 7: e49655.

\section{MCO answers}

$1 \mathrm{a} \quad 2 \mathrm{c} \quad 3 \mathrm{~d} \quad 4 \mathrm{~b} \quad 5 \mathrm{~d}$ 


\section{MCOs}

Select the single best option for each question stem

1 Regarding children's experience of public care:

a foster carers may abuse the children placed with them

b the majority of children report negatively about their experience in care

c breakdown of a foster placement is a rare event

$\mathrm{d}$ turnover among children's social workers is low

e residential workers tend to be highly qualified.

\section{Regarding childhood adversity:}

a the majority of children enter public care because of the death of their parents

b parents with mental disorders are not at increased risk of maltreating their children

c individuals with a history of maltreatment show increased rates of mental disorders

d there is no association between adult problem sexual behaviour and a history of maltreatment

e there is no association between poor physical health and a history of maltreatment.
3 Regarding children's experiences of adoption:

a the longer a child can stay with the birth family the better the adult outcome

b more adoptees report negatively about their adoption experience than positively

c adoptive parents should wait until the child has reached adulthood before disclosing their adoptive status

d adoptees with mental health difficulties are more likely to report negative adoption experiences than those without mental health difficulties

e about 20 in 100 adoptive placements break down.

4 Regarding providing a reliable diagnosis and prognosis for individuals affected by public care or adoption:

a information on parental mental health status is usually readily available

b symptoms in several domains may not meet threshold criteria for a specific diagnosis but still affect functioning c the multifaceted mental health difficulties of such individuals can be comprehensively captured by conventional diagnostic systems

$d$ the diagnostic category of developmental trauma disorder has been included in DSM-5

e there are no follow-up studies tracing their development into adulthood.

5 Regarding clinical work with individuals affected by public care or adoption:

a the effects of childhood maltreatment on adult health behaviour are well understood

b most individuals affected by public care or adoption have severe mental health difficulties

c there is no need to ask about experiences of care and adoption because patients will always disclose this information

d Multidimensional Treatment Foster Care may be superior to usual care placements for adolescents with serious antisocial behaviour problems

e transitions from child mental health services to adult services usually go smoothly. 